\title{
A PRODUÇÃO DO TEXTO ESCRITO: DO CONTEXTO UNIVERSITÁRIO À PRÁTICA DE SALA DE AULA ${ }^{1}$
}

\author{
Glaucia Muniz Proença Lara
}

\begin{abstract}
Resumo: Tomando a produção do texto escrito como nosso objeto de reflexão, buscamos responder à pergunta: o que diz e o que faz a universidade (contexto de formação do professor) e o que diz e o que faz, $o$ professor dos níveis fundamental e médio no cotidiano escolar (contexto de atuação desse profissional)? À luz de diferentes teorias lingüísticas, verificamos a defasagem que existe entre os dois contextos, uma vez que os egressos das universidades não têm sido capazes de fazer uma "ponte" entre o conhecimento teórico aprendido na universidade e a prática de sala de aula. Sem a pretensão de esgotar o assunto, apontamos alguns caminhos que nos parecem relevantes para a solução do problema, tais como a ampliação do espaço da "Lingüística" na grade curricular dos cursos de Letras, uma maior integração entre as disciplinas "Lingüística" e "Língua Portuguesa" e a proposição de oficinas de lingüística aplicada em que se busque a articulação entre teoria e prática.
\end{abstract}

Palavras-chave: produção textual; Universidade; ensino fundamental e médio.

\section{Alguns aspectos introdutórios}

Partindo do tema mais amplo "os significados da escrita no universo cultural do profissional de educação", buscaremos respostas para uma série de perguntas que se colocam no centro da discussão sobre a formação do professor no que tange às práticas de leitura e escrita. Privilegiaremos aqui a produção do texto escrito, que tem sido nosso objeto de estudo nos últimos anos. Afinal de contas, que concepções de língua/linguagem e de sujeito estão subjacentes aos discursos e às práticas que orientam a produção textual na universidade (contexto de formação do professor) e na escola dos níveis fundamental e médio (contexto de atuação desse profissional)? Em que medida a história de vida - sobretudo escolar - desse sujeito interfere na sua ação pedagógica voltada para a formação de "escritores"? Como se faz a "ponte" entre a prática de formação do professor e sua prática docente? Tudo isso pode ser resumido na pergunta: o que dizem e o que fazem as instâncias de formação, as universidades, e o que dizem e o que fazem os professores no cotidiano da sala de aula, quando o objeto é a escrita?

\footnotetext{
${ }^{1}$ A primeira versão deste trabalho foi apresentada na mesa-redonda "Práticas de leitura e escrita: o que dizem e o que fazem as instituições de formação do professor? O que dizem e fazem os professores?", no $14^{\circ}$ Congresso de Leitura do Brasil (COLE), realizado pela ALB/UNICAMP, em julho de 2003.

2 Professora da Faculdade de Letras da Universidade Federal de Minas Gerais (UFMG). Doutora em Semiótica e Lingüística Geral pela Universidade de São Paulo (USP).
} 
Será esse, portanto, o eixo básico de nossa reflexão sobre a produção do texto escrito no contexto escolar, sem deixar de lado, evidentemente, a questão da leitura, do ensino da gramática e da abordagem do texto oral, que são também objeto das práticas de formação e de atuação do profissional de Letras. Não temos a pretensão de esgotar o assunto nem tampouco de fornecer "receitas" para solucionar uma questão que se nos afigura complexa, mas apenas avançar um pouco mais na discussão do que nós, professores e pesquisadores da universidade, podemos fazer para minimizar (ou mesmo impedir) a defasagem que se tem observado entre o que o professor do ensino fundamental e médio aprende nos cursos de Letras e o que ele faz com esse conhecimento na sua prática docente efetiva.

\section{O que diz e o que faz a universidade}

Nas últimas décadas, idéias oriundas sobretudo dos meios acadêmicos vieram desestabilizar o ensino de língua portuguesa no Brasil, ensino esse que, até então, era fortemente marcado por uma perspectiva metalingüística e normativa, calcada na gramática.

Como bem mostram Silva \& Cox (2002, p. 27-28), "esse movimento de renovação paradigmática do ensino de língua materna foi, na verdade, desencadeado pela renovação paradigmática da lingüística". Assim, a chegada ao país, no final da década de 70, da lingüística da enunciação e das teorias do texto/discurso provocou mudanças não apenas no campo do estudo científico da língua/linguagem, como também no do ensino, rompendo a hegemonia de uma lingüística da língua, de cunho estruturalista ou gerativo-transformacional, que não ultrapassava o nível da frase e que se atinha a aspectos formais.

Na mesma direção de Silva \& Cox (2002), Castilho, no início década de 90, já apontava as mudanças epistemológicas que, então, se processavam nos estudos lingüísticos:

(...) há uma crise científica em marcha. O pêndulo que assinala o paradigma lingüístico vigente novamente oscila, e vai deixando o pólo da linguagem como enunciado, e se desloca para o pólo da linguagem como enunciação. Já não se postula mais a linguagem como código abstrato, e se incorporam às análises do enunciado as condições de sua produção. Em conseqüência, o eixo da indagação científica se desloca da análise taxonômica dos produtos lingüísticos para a análise dos processos psicossociais que constituem esses produtos. (CASTILHO, 1990, p. 106).

No âmbito do ensino, essa mudança provocou uma (re)discussão de questões ligadas à correção lingüística, ao enfoque gramatical da língua na escola e às práticas de leitura e de escrita que, sendo reorientadas por uma concepção interacionista da linguagem, passaram a privilegiar a noção de uso, tomando o texto como unidade básica do ensino e propondo um trabalho com os diferentes gêneros em que os textos se inscrevem, conforme se pode constatar nos Parâmetros Curriculares Nacionais de Língua Portuguesa - $5^{a}$ a $8^{a}$ Séries (1998, p. 23 ).

Partindo de críticas ao ensino tradicional, como a excessiva escolarização das atividades de leitura e produção de textos; o uso do texto como expediente para ensinar valores morais e como pretexto para o tratamento de aspectos gramaticais; e a excessiva valorização da gramática normativa, com um ensino descontextualizado da metalinguagem, os PCNs (1998, p. 18) propuseram uma ampla revisão das práticas de ensino da língua, como se pode constatar no trecho transcrito abaixo: 
Tomando-se a linguagem como atividade discursiva, o texto como unidade de ensino e a noção de gramática como relativa ao conhecimento que o falante tem de sua linguagem, as atividades curriculares de Língua Portuguesa correspondem, principalmente, a atividades discursivas: uma prática constante de escuta de textos orais e leitura de textos escritos e de produção de textos orais e escritos, que devem permitir, por meio da análise e reflexão sobre os múltiplos aspectos envolvidos, a expansão e construção de instrumentos que permitam ao aluno, progressivamente, ampliar sua competência discursiva.

Embora essa perspectiva didática voltada para a produção e interpretação de textos e para uma abordagem gramatical vinculada às práticas de linguagem já viesse sendo proposta há algum tempo por estudiosos e pesquisadores ${ }^{3}$ comprometidos com um ensino que assegurasse ao aluno, via domínio da língua/linguagem, a plena participação social, ela só foi instituída oficialmente, no final dos anos 90, com a publicação e a divulgação dos PCNs pelo Ministério da Educação. Passou, assim, a integrar os currículos das universidades e os programas de exames nacionais (como o "Provão"), tornando-se objeto de análise e discussão.

A questão que se coloca, no entanto, é se a oficialização dessa proposta, que traz o mérito inegável de mostrar-se coerente com as descobertas recentes da ciência lingüística, tem sido acompanhada, efetivamente, de mudanças no dia-a-dia da sala de aula.

Nesse sentido, Silva \& Cox (2002, p. 45-46) afirmam que os resultados dos primeiros anos de implantação dos PCNs não são nada animadores, uma vez que eles foram urdidos por "professores universitários em dia com a mudança paradigmática ocorrida na lingüística, mas com pouco senso de realidade das condições em que os atuais professores de português teriam para realizá-la". Além disso, essa nova proposta de ensino não veio acompanhada por uma ampla mudança nos currículos dos cursos de Letras, onde disciplinas como a Sociolingüística e a Lingüística Textual ainda ocupam um lugar menor e onde conceitos como discurso, texto, gêneros textuais, condições de produção, entre outros, não são de domínio comum. Assim, se os PCNs têm sido repassados, de forma "light", para os professores do ensino fundamental e médio, em seminários, encontros e cursos rápidos de atualização, isso não tem sido suficiente para "enraizar uma nova prática conseqüente", não chegando a causar mais do que um "malestar em relação às antigas concepções".

Em outras palavras, os professores, objeto de treinamento desses eventos, sabem que tanto o ponto de partida como a finalidade do ensino da língua é a produção/recepção de textos, inseridos em diferentes gêneros; que a prática pedagógica deve organizar-se em torno do eixo uso $\Rightarrow$ reflexão $\Rightarrow$ uso; que a seleção de textos para leitura ou escuta deve articular-se à prática de produção e à de análise lingüística, formando um tripé que permita ao aluno desenvolver sua competência lingüística e textual/discursiva, tornando-se capaz de produzir diferentes efeitos de sentido a partir de diferentes condições de produção do texto oral e escrito. Ou seja: tais professores têm em mente uma série de "princípios norteadores", mas não têm sido capazes de operacionalizá-los na sua prática cotidiana.

Para Neves (2002, p. 265), essa dificuldade decorre, em grande parte, da formação (lingüística) dos professores do ensino fundamental e médio. Refletindo sobre

\footnotetext{
${ }^{3}$ Entre outros, lembramos João Wanderley Geraldi que, aliás, é também mencionado nos PCNs. Em seu livro O texto na sala de aula (1 $1^{\text {a }}$ edição de 1984), o autor já propõe um trabalho integrado de leitura, produção e gramática a partir do texto.
} 
essa questão, a autora se pergunta se esses professores sabem exatamente o que fazer com aquilo que trouxeram de seu curso de Letras, com os conhecimentos adquiridos na disciplina "Lingüística", ou se eles simplesmente assumem que uma coisa (a lingüística) não tem nada a ver com a outra (o ensino da língua) e partem para o continuísmo de atividades e processos. A partir daí, torna-se necessário, portanto, (re)pensar o ensino de lingüística na universidade para que os alunos (futuros professores) tenham as mínimas condições de dele tirar orientação e conteúdo para o trabalho com a linguagem de seus alunos.

\section{O que diz e o que faz o professor}

Em pesquisa realizada anteriormente (LARA, 2004), constatamos que os professores de português do ensino fundamental e médio vêem a língua não como ela é, na realidade: um objeto dinâmico, pluriforme e multifacetado, mas como um bloco estático, uniforme e homogêneo, que se garante pela obediência a um conjunto limitado de normas (gramática, tomada no seu sentido prescritivo) que orientam o "bem falar" e, sobretudo, o "bem escrever". Mostram-se, desse modo, pouco familiarizados com o que tem sido feito e proposto no âmbito dos estudos sobre a língua/linguagem pela comunidade científica, apesar de terem tido, na grade curricular do curso de Letras, a disciplina "Lingüística", o que, aliás, vai ao encontro das opiniões manifestadas por Silva \& Cox (2002) e por Neves (2002).

Assim, se esses mesmos professores, quando indagados sobre sua atuação no ensino da língua, afirmam que buscam uma maior valorização da leitura e da escrita, que trabalham o ensino da gramática através do texto e que respeitam a "bagagem" lingüística que o aluno traz do seu meio social, percebemos que essa proposta não vem aliada, como era de esperar, a um conhecimento teórico profundo, a uma base lingüística sólida que possa fundamentar as práticas cotidianas.

Essa defasagem teórica, entre outros fatores, permite que o professor mantenha uma atitude purista em relação à língua e ao seu usuário e continue a proferir um discurso predominantemente normativo, o que, sem dúvida alguma, vai estar na base de um ensino improdutivo que, tomando a norma culta como a "verdadeira" língua (a melhor, a mais correta), continua privilegiando o uso da metalinguagem e a obediência às regras da gramática normativa ${ }^{4}$.

Diante dessas concepções de língua e linguagem que alimentam o ensino, os alunos acabam sendo expostos a modelos de leitura e escrita que privilegiam a correção gramatical (os aspectos microtextuais) em detrimento de aspectos macrotextuais, como, por exemplo, a coerência ou a seleção/organização de argumentos em defesa de um ponto de vista.

No que diz respeito à produção textual, o professor sabe, por exemplo, que, de acordo com os PCNs (1998, p. 78-79), a refacção faz parte do processo de escrita e que, portanto, um texto pronto será sempre produto de sucessivas versões. Esse procedimento justifica-se na medida em que permite ao aluno ser leitor do próprio texto,

\footnotetext{
${ }^{4}$ Neves (1991, p. 9-11), em pesquisa feita com professores dos antigos $1^{\circ}$ e $2^{\circ}$ graus, constatou que todos eles, de um modo ou de outro, "ensinam" gramática, com o objetivo principal de levar o aluno a "falar e escrever melhor". Assim, se eles substituíram, em grande parte, o ensino da gramática normativa pelo da gramática descritiva, conservam, no entanto, a idéia de que a gramática poderia (ou deveria) servir para subsidiar um "melhor" desempenho lingüístico dos alunos. Na realidade, parece-nos que na medida em que se propõe descrever um único uso (a norma culta) tido como o mais correto e elegante, a escola não se afasta muito da perspectiva normativa tradicional, mas apenas a "moderniza", como, aliás, a própria autora reconhece.
} 
distanciando-se dele para assumir uma postura crítica, e dá ao professor condições de elaborar, entre uma etapa e outra da reformulação, atividades e exercícios que possibilitem ao aluno apropriar-se progressivamente das habilidades necessárias à autocorreção (não apenas um conjunto de instrumentos lingüístico-discursivos, mas também técnicas de revisão).

O professor, no entanto, dada a sua história escolar de escrita em que, via de regra, focaliza-se o produto final e não o processo, não foi habituado a tomar seu próprio texto como objeto de análise e reformulação. Assim, ele tende a agir da mesma forma quando se vê diante da necessidade de corrigir/avaliar as redações de seus alunos.

Por mais que tenha discutido os princípios que norteiam a autocorreção, o que ele acaba fazendo é propor sucessivas etapas de higienização do texto, deixando de lado a oportunidade de abordar com seus alunos aspectos relacionados ao próprio processo de produção, tais como o levantamento e a seleção de idéias que sejam adequadas e relevantes para o assunto em pauta; a organização coerente dos fatos (dados, argumentos), tanto do ponto de vista interno (isto é, a compatibilidade das idéias apresentadas entre si e com o tema proposto) quanto externo (ou seja, a não-contradição entre as informações veiculadas no texto e o conhecimento de mundo do leitor); os efeitos de sentido que se criam a partir de determinados procedimentos lingüísticodiscursivos (como, por exemplo, o uso da $1^{a}$ pessoa do singular, somado a adjetivos e advérbios de cunho apreciativo, para criar um efeito de sentido de subjetividade), entre outros aspectos importantes.

Negligencia, portanto, a discussão de questões relacionadas às dimensões pragmática e semântica da linguagem para privilegiar a dimensão gramatical. Além do mais, julgando extremamente complexa a tarefa de delegar progressivamente a correção dos textos para os próprios alunos (afinal de contas, ele mesmo não foi preparado para ser um leitor crítico daquilo que produz), o professor não consegue distribuir tarefas, de modo a tornar-se um mediador no processo de produção/refacção de textos, mantendo a atividade de correção centrada sobre si mesmo. Com isso, preserva seu status de interlocutor privilegiado - e, não raras vezes, único - do aluno, mostrando-se, em geral, mais interessado em expurgar o texto de seus "desvios gramaticais" do que em saber efetivamente o que seu produtor pensa sobre um determinado assunto. É a história do aluno perpetuando-se na prática do professor.

É interessante observar também que, se os critérios de avaliação de provas de redação como as do Exame Nacional de Ensino Médio (e, na esteira do ENEM, as de vários vestibulares) flexibilizaram a noção de "erro", admitindo um aluno que apresente desvios em relação à norma culta, eles, por outro lado, passaram a normatizar a produção textual, propondo "fôrmas" em que o texto deve ser encaixado. Assim, o ENEM instituiu o modelo único de redação: o texto do tipo dissertativo-argumentativo (desvinculado, portanto, de um gênero específico: uma carta, uma notícia, um anúncio publicitário, entre outros) que parte da problematização do tema para a apresentação compulsória de soluções. Tanto é que, se o aluno não apontar propostas viáveis para a resolução do problema levantado, será penalizado na competência $\mathrm{V}^{5}$.

\footnotetext{
5 A planilha de correção do ENEM propõe a avaliação de cinco competências: I - demonstrar domínio da norma culta da língua escrita; II - compreender a proposta de redação e aplicar conceitos das várias áreas de conhecimento para desenvolver o tema, dentro dos limites estruturais do texto dissertativoargumentativo; III - selecionar, relacionar, organizar e interpretar informações, fatos, opiniões e argumentos em defesa de um ponto de vista; IV - demonstrar conhecimento dos mecanismos lingüísticos necessários para a construção da argumentação; V - elaborar proposta de intervenção para o problema abordado, demonstrando respeito aos direitos humanos. Essas competências subdividem-se em quatro níveis que vão da maior (quatro) à menor nota (um).
} 
Diante disso, a escola dos níveis fundamental e, sobretudo, médio viu-se obrigada a investir no treinamento de modelos oficiais de produção de texto, deixando de lado a oportunidade de aprofundar o trabalho com uma diversidade de gêneros e tipos textuais que propiciariam ao aluno o aprimoramento de sua competência na escrita. Por mais que seja importante sensibilizar esse aluno para a realidade que o rodeia, não se pode obrigá-lo a adotar, de uma vez por todas, como faz o ENEM, o esquema problema $\Rightarrow$ solução para tratar de aspectos dessa realidade. Agir dessa forma é submeter o aluno a esquemas pré-fabricados que não lhe dão espaço para posicionarse criticamente, até mesmo contestando a proposta, se for o caso.

No nosso entender, dominar os mecanismos específicos do texto (escrito) não implica acreditar em modelos fixos e estanques, em receitas e fórmulas prontas, que correspondam a uma única possibilidade correta ou aceitável de escrever, pois isso negaria o "princípio de multiplicidade", que, segundo Orlandi (1983), é inerente à linguagem. Implica, isto sim, saber que, entre a fixidez, a rigidez e a completa liberdade sem margens, há, na construção histórica de conhecimentos compartilhados, configurações textuais mais ou menos consensuais que são relevantes para determinar o que faz de um texto uma unidade, um todo significativo (e não um amontoado aleatório de frases), inscrito num determinado gênero. O que há, portanto, no caso dos textos, são tendências e regularidades, não regras preditivas e prescritivas, como faz crer a adoção do "modelo único" de redação.

Nesse caso, como afirma Geraldi (1985), não temos um "sujeito" que diz efetivamente a sua palavra, que produz um "texto", mas alguém que se limita a reunir informações e fragmentos de informações que lhe foram passadas pela escola, para devolvê-las, em forma de "redação"6 à própria escola, o que nos lembra o "sujeito assujeitado" da primeira fase da $\mathrm{AD}^{7}$.

Um outro ponto importante merece ser levantando nesta discussão sobre a prática escolar de produção de textos: o que o professor de português do ensino fundamental e médio diz e faz esteia-se, em grande parte, no que diz e faz o livro didático.

Nesse sentido, Reinaldo (2002, p. 90-95), discutindo os pressupostos básicos que orientam o ensino de produção de textos no livro didático, aponta várias questões problemáticas. Por exemplo: a) o manual do professor destaca a importância de se observarem os fatores de textualidade, mas no desenvolvimento da proposta do livro não há atividades que explorem esse aspecto na construção do texto; b) as reflexões sobre a textualidade não contemplam o gênero textual que será objeto da produção; c) a tipologia clássica - narração, descrição, dissertação - é tomada como referência central para o ensino da escritura, desconsiderando (ou, o que é pior, confundindo) a distinção entre gêneros (isto é, conjuntos de enunciados relativamente estáveis de uso concreto na sociedade) e tipos ou sequiências textuais (isto é, estruturas relativamente autônomas, dotadas de uma organização interna que lhes é própria e que podem figurar nos diversos gêneros de circulação social); d) os autores dos manuais escolares, embora estejam sensibilizados para a inclusão de textos representativos dos diversos gêneros como

\footnotetext{
6 Apesar de julgar pertinente a distinção entre "texto" e "redação" proposta por Geraldi (1985), não a estamos adotando no presente trabalho. Aqui os dois termos devem ser tomados como sinônimos.

${ }^{7}$ Embora o indivíduo não possa deixar de ser "interpelado em sujeito pela ideologia", como diz Pêcheux (1988, p. 151), inspirado em Althusser, concordamos com Orlandi (1987, p. 189), para quem não existe "nem um sujeito absolutamente dono de si, nem um sujeito totalmente determinado pelo que lhe vem de fora". Isso quer dizer que é sempre possível deslocar o mesmo, o garantido, o sedimentado, em busca da polissemia e da criatividade (ORLANDI, 1988, p. 11-27). Acontece que a imposição de "modelos" fixos para a produção textual acaba favorecendo muito mais a paráfrase e a produtividade.
} 
objeto de leitura, nem sempre apresentam orientação metodológica suficiente para a produção desses textos; e) inspirados nos PCNs, alguns livros didáticos propõem uma etapa de revisão individual do texto, sem, no entanto, fornecer parâmetros para a revisão, o que acaba resultando não numa reformulação de idéias, como fazem os redatores experientes, mas num puro ato mecânico (higienização na cópia do primeiro texto) pelos redatores inexperientes.

Enfim, em relação ao ensino de produção de texto, a orientação predominantemente sociointeracionista, de inspiração discursiva, que se faz presente nos PCNs não tem sido contemplada em muitos livros didáticos. Estes, segundo Reinaldo (2002, p. 96-97), preferem uma "abordagem codificadora, de inspiração estruturalista (os textos a serem produzidos tendem a ser tratados como pura forma linguiística a ser dominada), em detrimento da abordagem textual-discursiva (os textos a serem produzidos são considerados quanto aos mecanismos de textualização e quanto à situação comunicativa do gênero a ela correspondente)".

Assim, conforme constata a autora, a eficiência na condução do processo de ensino-aprendizagem fica praticamente condicionada à qualidade da formação do professor, já que este não conta com subsídios teóricos suficientes nos manuais a ele destinados (REINALDO, 2002, p. 101).

Como a formação do professor de português também deixa a desejar, uma vez que, conforme vimos, ele não tem sido capaz de fazer a mediação entre os conhecimentos teóricos adquiridos na disciplina "Lingüística" e a aplicação desses conhecimentos na sua prática docente, podemos concluir que esse profissional fica relegado à sua própria sorte. É, portanto, mais fácil enveredar por caminhos já traçados - porque mais firmes - do que buscar alternativas compatíveis com uma abordagem interacionista da linguagem para o ensino da produção de textos na escola. Afinal, como dizem Silva \& Cox (2002, p. 45), "o que representam trinta anos de lingüística do discurso contra uma tradição gramatical cultivada com devoção por mais de dois mil anos?"

Nesse sentido, o professor, mais uma vez, limita-se a reproduzir sua histórica escolar de escrita, ao invés de romper com ela e buscar outras formas (mais produtivas) de trabalhar o texto, de modo a tornar seus alunos leitores/"escritores" competentes, capazes, portanto, de interpretar diferentes textos, inseridos em diferentes gêneros que circulam socialmente, e de assumir a palavra, produzindo textos eficazes nas mais variadas situações de interlocução.

\section{Uma luz no fim do túnel}

$\mathrm{Na}$ seção anterior, chegamos a um impasse: como investir na formação do professor de português para que este consiga fazer a "ponte" entre o conhecimento teórico aprendido na universidade e a prática de sala de aula no ensino fundamental e médio? Como conscientizá-lo e instrumentalizá-lo para que ele possa romper com a sua história escolar de escrita e buscar alternativas mais viáveis para a prática de produção de textos na escola?

Embora se trate de uma questão complexa e que não nos parece possível de ser resolvida a curto prazo, acreditamos, com base nos autores pesquisados e na nossa própria experiência, que podemos dar algumas respostas possíveis às questões levantadas acima.

Se assumimos com Neves (2002, p. 266-267) que "o conhecimento das diferentes teorias lingüísticas é inquestionavelmente necessário para que o futuro professor de português entenda o fenômeno da linguagem e o funcionamento das 
línguas", é preciso repensar o papel da "Lingüística" nos cursos de Letras, já que aparentemente os egressos das universidades não sabem o que fazer com essa disciplina quando se encontram na outra ponta: a do ensino nos níveis fundamental e médio. A autora considera que hoje os professores desses níveis decidiram "esquecer que um dia aprenderam (...) lingüística, embora guardem 'ranços' da atividade."

Foi a mesma conclusão a que chegamos em nossa pesquisa anterior (LARA, 2004) Atualmente parece ser "lingüisticamente correto" assumir e reproduzir o discurso da lingüística. Entretanto, a maioria dos professores do ensino fundamental e médio (re)interpreta esse discurso com suas próprias categorias, fruto de um ensino gramaticalista e preconceituoso que alimenta e é alimentado por uma visão redutora da língua, e passa a (re)utilizá-lo de forma fragmentada, descontexualizada e mesmo, por vezes, distorcida naquilo que diz e faz. Ocorre, assim, uma espécie de vulgarização (desvirtuada) do discurso científico, o que revela a má formação e o despreparo desses profissionais.

Logo, para que lhes seja possível mudar de discurso (e de postura), é preciso que eles possuam, de fato, um conhecimento amplo e profundo sobre a língua (sua estrutura, seus usos, suas modalidades e variedades), o que parece estar ligado à necessidade de investimento contínuo na capacitação desses professores, quer através da melhoria dos cursos de graduação e pós-graduação na área de Letras, com a conseqüente ampliação do espaço da linguiística na grade curricular desses cursos, quer por meio da oferta freqüente de cursos de reciclagem e atualização. Parece-nos também necessária uma maior integração entre as disciplinas "Lingüística" e "Língua Portuguesa", cujos conteúdos são, muitas vezes, trabalhados de forma estanque e isolada, bem como a proposição de oficinas de lingüística aplicada em que se busque a articulação entre teoria e prática. ${ }^{8}$

Por outro lado, se o que se pretende é centrar o ensino de português no "tripé" das práticas: a prática de leitura e de escuta de textos, a prática de produção de textos orais e escritos e a prática de análise lingüística, trabalhadas como práticas articuladas e complementares, não tem sentido que a escola dos níveis fundamental e médio continue a propor aulas separadas de leitura, de redação e de gramática normativa (ou descritiva), como se houvesse uma dicotomia irreversível entre a língua e seu sistema, de um lado, e o uso lingüístico do outro; como se houvesse gramática fora do texto/discurso.

As atividades de leitura e produção devem ser integradas. Expor os alunos a uma variedade de textos não apenas escritos, mas também orais, lhes dá a oportunidade ímpar de observar como escritores proficientes, levando em conta as condições de produção e as coerções do gênero em que cada texto se inscreve, unem conteúdo e expressão, num processo de composição eficaz. Esses textos passam, assim, a servir de "modelos" para a construção de uma "norma" textual (aqui entendida como consenso, não como prescrição) que esses alunos passarão a utilizar na produção de seus próprios textos (LARA, 1999).

Se, enquanto contraparte da leitura, a produção de textos busca inscrever-se numa perspectiva enunciativa, é preciso romper com a artificialidade do contexto escolar em que as respostas às questões o que dizer, para quem dizer e como dizer, que intervêm a título de condições de produção, apontam invariavelmente para o professor.

\footnotetext{
${ }^{8}$ No caso da produção do texto escrito, tais oficinas se orientariam pelos princípios teórico-metodológicos da Lingüística Textual (noções de texto e de textualidade) e da Análise do Discurso de linha francesa -$\mathrm{AD}$ (condições de produção, interdiscursividade), entre outros. Trata-se, evidentemente, de abordagens distintas, mas que, a nosso ver, podem complementar-se para dar conta dos problemas de ordem diversa com que se defronta o professor na sala de aula.
} 
Como afirma Brito (1985, p. 123), na redação, “o interlocutor acaba não apenas por impor-se ao locutor, mas também por ameaçar destruir o próprio papel de sujeito que este deveria ter numa relação intersubjetiva".

Se variadas são as situações sociais de interlocução também variadas devem ser as respostas às três perguntas mencionadas acima, o que determinará diferentes textos, produzidos em consonância com os diversos gêneros historicamente instituídos. Nesse caso, não se pode restringir a circulação do texto apenas ao par aluno/professor; é preciso fazer com que ele circule entre diferentes interlocutores, que estejam, efetivamente, interessados no que o locutor tem a dizer sobre um determinado assunto (e não apenas no como ele o faz).

Uma das formas de promover a circulação de textos é descentrar a correção, delegando-a, progressivamente, aos alunos até que se chegue à autocorreção, em que cada um se torna leitor/avaliador do próprio texto, constituindo-se o professor em mediador desse processo, uma vez que ele se transforma de único leitor em um entre os possíveis leitores do texto do aluno. A socialização da produção textual tem a inegável vantagem de recuperar o caráter interlocutivo do processo e garantir a constituição dos leitores e produtores em sujeitos do fazer lingüístico.

É a partir desse trabalho conjunto de correção, rumo à autocorreção, que se torna possível articular a prática de análise linguiística às práticas de leitura e produção de textos, completando o "tripé" em que se esteia o ensino de português.

Os PCNs (1998, p. 78-79) já nos alertam que "a prática de análise linguiística não é uma nova denominação para ensino de gramática". Se tomamos o texto como unidade de ensino, os aspectos a serem tematizados não se restringem apenas à dimensão gramatical, mas abarcam também as dimensões pragmática e semântica da linguagem que são inerentes à própria atividade discursiva. Um dos aspectos fundamentais da prática de análise lingüística é a refacção dos textos produzidos pelos próprios alunos que, conforme já apontamos, parte da refacção coletiva, em que professor e alunos juntos assinalam dificuldades (abordando os aspectos tanto micro quanto macrotextuais) e tentam solucioná-las, à autocorreção, passando pelo trabalho em pequenos grupos e em duplas. Amplia-se, dessa forma, gradativamente, o grau de dificuldade da tarefa, ao mesmo tempo em que se dilui a imagem autoritária do professor - enquanto interlocutor privilegiado a quem cabe julgar e decidir - num trabalho que procura dar vez e voz aos diferentes sujeitos que interagem no espaço escolar, instaurando-os como "coenunciadores".

Entretanto, sair progressivamente de cena não implica deixar o aluno à sua própria sorte na tarefa de refacção. Cabe ao professor orientar o processo em qualquer uma de suas etapas, mesmo na fase final (a de autocorreção) em que se supõe um aluno dotado de maior senso crítico, autonomia para tomar decisões e capacidade de avaliação. Nessa orientação, longe de impor ou fixar o que deve ser feito, o professor fornece pistas de como os alunos podem detectar problemas e promover as alterações necessárias. Sem isso, esses alunos, pouco habituados a tomar seus próprios textos como objeto de reflexão, não serão capazes de levar a cabo a atividade de forma satisfatória. O ideal seria a construção de uma planilha de correção ou, como preferimos, um roteiro com "dicas" sobre os aspectos a serem observados no diagnóstico dos problemas, com vistas à posterior reformulação dos textos (vide LARA, 1999, p. 84).

A ênfase dada à reelaboração de um texto, até que se chegue a uma versão satisfatória, não apenas permite apreender as dificuldades e necessidades dos estudantes (que serão abordadas nos "conteúdos gramaticais"), mas também serve para mostrar a revisão como parte integrante - e fundamental - do processo de escrita, o que contribui 
para derrubar a falsa impressão, compartilhada por muitas pessoas dentro e fora do contexto escolar, de que só maus escritores precisam fazer rascunhos.

Apesar das inegáveis vantagens que a prática de análise lingüística e a refacção de textos apresentam no ensino da língua, muitos professores dos níveis fundamental e média relutam em adotá-las mais por falta de familiaridade com essas atividades do que por desinteresse ou má vontade. Seria, portanto, de suma importância que, na condição de alunos, ainda no âmbito universitário, esses (futuros) professores pudessem passar por experiências de produção de textos orientadas pelos princípios da autocorreção, o que poderia ser feito em oficinas de lingüística aplicada ou em disciplinas integradas ao currículo, como "Prática de leitura e produção de textos", "Redação e expressão oral" ou similares. Assim, tendo passado pelo processo na qualidade de alunos, eles teriam uma visão mais clara e mais bem fundamentada de como conduzi-lo quando assumissem a outra ponta do ensino - a docência.

Fica aqui a sugestão para que nós, professores universitários, possamos contribuir, de modo mais eficaz, na formação do profissional de Letras, instrumentalizando nossos alunos para que sejam capazes de articular as práticas de leitura, de produção de textos e de análise lingüística com mais competência - porque possuem conhecimentos teóricos suficientes para tanto - e maior segurança - porque sabem como essas práticas "funcionam" efetivamente.

\section{Considerações finais}

A título de conclusão, gostaríamos de enfatizar três pontos, entre tantos outros, que, a nosso ver, merecem consideração no que tange à prática de produção do texto escrito na escola, tomada aqui como nosso objeto privilegiado de análise:

a) É necessário transformar o ato pedagógico numa interlocução efetiva, num processo em que o escrever se justifique como prática histórico-social.

b) De nada adianta, no entanto, modificar técnicas e métodos empregados na sala de aula, se não se adota, concomitantemente, uma nova concepção de língua/linguagem - que passa a ser tomada como uma forma de ação intersubjetiva.

c) Essa nova concepção de língua/linguagem, por sua vez, implica um voltar de olhos para o processo, para as condições concretas de produção do texto escrito na escola, construindo não apenas uma nova metodologia, mas, principalmente, um novo conteúdo de ensino, em que se articulam e se complementam, em torno do texto, as práticas de leitura, de produção e de análise lingüística, integradas aos diferentes gêneros textuais.

Ora, embora já tenha sido oficializado pelos PCNs, esse novo conteúdo de ensino ainda não foi suficiente para enraizar uma nova prática conseqüente, sem a qual os parâmetros correm o risco de se manterem apenas como um conjunto de princípios teóricos, pouco articulado com a realidade do ensino fundamental e médio. Insistimos, mais uma vez, no papel fundamental que cabe a nós, docentes das universidades, de promover a passagem da teoria à prática, criando condições para que nossos alunos, futuros professores, saibam operacionalizar tais princípios no dia-a-dia da sala de aula. De nada adianta "atochar" o profissional de Letras de diferentes teorias lingüísticas, se ele não sabe, minimamente, o que fazer com elas no ensino da língua. Por mais que essas teorias sejam relevantes - e ninguém pode negar que são - para a sua formação.

É apenas nesse trabalho integrado que nos parece possível compatibilizar - ou, pelo menos, aproximar mais - o que diz e faz a universidade, de um lado, e o que diz e 
faz o professor do ensino fundamental e médio, do outro, questão maior que orientou nossa reflexão.

\title{
Referências Bibliográficas
}

BRASIL. SECRETARIA DE EDUCAÇÃO FUNDAMENTAL. Parâmetros curriculares nacionais: terceiro e quarto ciclos do ensino fundamental: língua portuguesa. Brasília: MEC/SEF, 1998.

BRITO, Percival L. Em terra de surdos-mudos. In: GERALDI, J. Wanderley (org.). $O$ texto na sala de aula. Cascavel: Assoeste, 1985.

CASTILHO, Ataliba T. de. Português falado e ensino da gramática. Letras de Hoje. Porto Alegre: PUC/RS. n. 25. p. 103-136, mar. 1990.

GERALDI, João Wanderley (org.). O texto na sala de aula. Cascavel: Assoeste, 1985.

LARA, Glaucia M. P. Autocorreção e auto-avaliação na produção de textos escolares: relato crítico de uma experiência. Campo Grande: Ed. UFMS, 1999.

. O que dizem da língua os que ensinam a língua: uma análise semiótica

do discurso do professor de português. Campo Grande: Ed. UFMS, 2004.

ORLANDI, Eni P. A linguagem e seu funcionamento. Campinas: Pontes, 1987.

NEVES, Maria Helena de M. Gramática na escola. São Paulo: Contexto, 1991.

Examinando os caminhos da disciplina lingüística nos cursos de Letras: por

onde se perdem suas lições na formação dos professores de português. In: . A gramática: história, teoria e análise, ensino. São Paulo, Ed. UNESP, 2002.

PÊCHEUX, Michel. Semântica e discurso. Campinas: Ed. UNICAMP, 1988.

REINALDO, Maria Augusta G. M. A orientação para produção de texto. In: DIONISIO, Angela P.; BEZERRA, Maria Auxiliadora (orgs.). O livro didático de português: múltiplos olhares. Rio de Janeiro: Lucerna, 2002.

SILVA, Mauro M. da; COX, Maria Inês P. As linhas mestras do novo paradigma de ensino de língua materna. Polifonia. Cuiabá: Ed. UFMT, n. 5, p. 27-48, 2002.

\begin{abstract}
Considering the production of written texts as our object of study, we try to answer the following question: what does the University do and say and what do the teachers of Junior High and High schools do and say about such na object in their classrooms? Resorting to different linguistic theories, we verify the gap that exists between these two contexts, which means that those who leave the University have not been able to link theoretical knowledge and practice. With no intention of exhausting the subject, we point out some possibilities that seem relevant to solve the problem, such as giving more time to "Linguistics" in the schedule, promoting the integration between "Linguistics" and "Portuguese" and offering students and teachers courses of Applied Linguistics so as to enable them to articulate theory and practice.
\end{abstract}

Keywords: written text production; University; Junior High and High schools. 
